\title{
CYTOKINE RELEASE SYNDROME AFTER CAR INFUSION IN PEDIATRIC PATIENTS WITH REFRACTORY/RELAPSED B-ALL: IS THERE A ROLE FOR DICLOFENAC?
}

Sara Napolitano, $\mathrm{MD}^{1}$, Giorgio Ottaviano, $\mathrm{MD}^{2}$, Laura Bettini, $\mathrm{MD}^{3}$, Vincenzo Russotto, $\mathrm{MD}^{4}$, Sonia Bonanomi, $\mathrm{MD}^{1}$, Attilio Rovelli, $\mathrm{MD}^{1}$, Andrea Biondi, $\mathrm{MD}^{1,5}$, Roberto Rona, $\mathrm{MD}^{4}$, Adriana Balduzzi, $\mathrm{MD}^{1,5}$

${ }^{1}$ Hematology-Oncology and Bone Marrow Transplantation Unit, Pediatric Dept., Monza and Brianza Foundation for Children and their Mums, San Gerardo Hospital, Lombardia, Monza, Italy

${ }^{2}$ Molecular and Cellular Immunology Unit, University College of London, Great Ormond Street Institute of Child Health, London, United Kingdom

${ }^{3}$ Monza and Brianza Foundation for Children and their Mums, Tettamanti Laboratory, Monza, Lombardia, Italy

${ }^{4}$ Department of Emergency and Intensive Care, University Hospital San Gerardo, Monza, Italy

${ }^{5}$ University of Milan-Bicocca, Monza, Italy

* Correspondence to:

Sara Napolitano, Pediatrician, Clinica Pediatrica, Università' degli Studi di Milano Bicocca, Monza, Italy; Contact Information: Fondazione MBBM / Ospedale San Gerardo, Via Pergolesi 33, 20900 Monza (MB), Italy, tel +39 039-233.2442, fax .3523, e-mail: snapolitano@fondazionembbm.it

Main text word count: 2532

Abstract word count: $\quad 244$ 


\begin{abstract}
Background: Cytokine release syndrome (CRS) is a major complication after chimeric-antigen receptor (CAR) T cell treatment, characterized by an uncontrolled sistemic inflammatory reaction. The potential role of diclofenac in the management of CRS has been investigated in five pediatric patients treated for relapsed/refractory B-lineage acute lymphoblastic leukemia.

Procedure: in case of persistent fever with fever-free intervals shorter than 3 hours, diclofenac continuous infusion was initiated, at the starting dose of $0.5 \mathrm{mg} / \mathrm{Kg} /$ day, the lowest effective pediatric dose, in our experience, possibly escalated up to $1 \mathrm{mg} / \mathrm{Kg} /$ day, as per institutional guidelines.

Results: CRS occurred at a median of 20 hours (range 8-27) after tisagenlecleucel infusion. Diclofenac was started at a median of 20 hours (range 13-33) after fever onset. A mean of 3,07 febrile peaks without diclofenac and 0,95 with diclofenac were reported (p-value 0.02). A clinical benefit was achieved by hampering the progression of tachypnea and tachycardia. Despite fever control, CRS progressed in four of the five patients and hypotension requiring vasopressors, fluid retention, besides hypoxia, occurred. Vasopressors were followed by 1-2 doses of tocilizumab (one in patient 2 and two in patients 3, 4, and 5), plus steroids in patients 4 and 5.

Conclusion: based on a limited number of patients, diclofenac leads to a better fever control, which translates into symptom relief and improvement of tachycardia, but could not prevent the progression of CRS.
\end{abstract}




\section{INTRODUCTION}

Diclofenac is a commonly prescribed non-steroidal anti-inflammatory drug (NSAID) with analgesic, anti-inflammatory, and antipyretic properties, which has been proven effective in a variety of acute and chronic pain and inflammatory conditions ${ }^{1 .}$ The principal mechanism of action is the inhibition of prostaglandin synthesis by the inhibition of cyclooxygenase-1 (COX-1) and cyclooxygenase-2 (COX-2) with relative equipotency. The binding of NSAIDs to COX isozymes inhibits the synthesis of prostanoids (prostaglandin PGE2, PGD2, PGF2, prostacyclin PGI2 and thromboxane TXA2). PGE2 is the dominant prostanoid produced in inflammation and the inhibition of its synthesis is considered the main mechanism of the potent analgesic and anti-inflammatory properties of these agents. Moreover, it has been demonstrated that diclofenac has higher selectivity for COX-2 than COX-12. In a cohort of consecutive unselected Intensive Care Unit (ICU) patients (including children) with fever $\left(38.9^{\circ} \mathrm{C}-41.3^{\circ} \mathrm{C}\right)$ not responsive to paracetamol, diclofenac sodium (starting dose $0.2 \mathrm{mg} / \mathrm{kg}$ intravenous - i.v.) was effective in reducing body temperature in the majority of the investigated patients, with no major side effects ${ }^{3}$. Continuous infusion of low-dose diclofenac allows to achieve fever control with no major cerebral or systemic side effects ${ }^{4,5}$. Renal function impairment represents a potential side effect, but it is expected to be transient/reversible, preventable by fluid optimization and infrequent in pediatrics.

The aim of this study is to describe the possible role of low-dose i.v. continuous infusion diclofenac in the management of cytokine release syndrome (CRS). CRS is an uncontrolled systemic inflammatory reaction resulting from a massive release of cytokines due to the interaction between tumor and immune effector cells ${ }^{6}$. The initial source of cytokines can be either the target cells themselves or the immune cells that have been recruited to the tumor site. This condition leads to excessive activation of immune cells, especially macrophages, which induces a further release of cytokines, like IL-1, IL-6, IL-8, IL-10, and MCP-1, culminating in a cytokine storm with an enhanced inflammatory response ${ }^{6,7,8 .}$ The clinical pattern of CRS ranges from mild to severe life-threatening symptoms (grade 1 - 4) ( $^{9}$ Patients with CRS frequently present with fever, shivers, tachycardia, dyspnea, hypotension, fluid retention, malaise, headache, nausea, vomiting, rash, myalgia, arthralgia, and rigor. Respiratory symptoms such as dyspnea, tachypnea, and hypoxia occur frequently and severity may vary. Cardiac complications include tachycardia, hypotension, and sudden cardiac dysfunction. In addition, vascular leakage is common and presents as peripheral and pulmonary edema ${ }^{10,11}$. The severity of symptoms may correlate with serum

cytokine concentrations and duration of exposure to the inflammatory cytokine storm ${ }^{12}$. Finally, sever neurological symptoms can occur with and, less often, without CRS, since some interleukins could drive trafficking of immune cells in central nervous system ${ }^{7,9}$. 
Multiple grading systems have been used to clinically classify the severity of CRS, including the National Cancer Institute Common Terminology Criteria for Adverse Events, the Penn Grading Scale, the Lee Grading Scale, which, more recently, were merged into the ASTCT Grading $9,{ }^{11},{ }^{13},{ }^{14}$. In all of these scales, severe and life-threatening grades of CRS require advanced supportive care.

\section{PATIENTS AND METHODS}

All patients scheduled for receiving tisagenlecleucel were admitted in the Pediatric Transplant Unit for lymphodepleting chemotherapy and CAR-T cell infusion. In case CRS occurred, patients were managed in the ward, with the collaboration of the ICU medical staff, whenever appropriate. In case of lifethreatening CRS, when respiratory management included the possibility of invasive mechanical ventilation, patients were transferred to ICU.

For the purpose of this study, CRS was graded according to the ASTCT grading, but also according to the two alternative main scoring systems, namely U-Penn and Lee classifications, all summarized in Table 1.

In case of persistent fever with fever-free intervals shorter than 3 hours, diclofenac continuous infusion was initiated, at the starting dose of $0.5 \mathrm{mg} / \mathrm{Kg} /$ day, the lowest effective pediatric dose, in our experience, possibly escalated up to $1 \mathrm{mg} / \mathrm{Kg} /$ day, as per institutional guidelines.

Peripheral oxygen saturation $(\mathrm{SpO} 2)$, heart rate $(\mathrm{HR})$, noninvasive blood pressure (NBP), respiratory rate (RR) and body temperature (Temp) were recorded at least every 3 hours, more frequently or continuously if clinically appropriate. Blood tests (CBC, CRP, biochemistry, coagulation) were performed daily to assess and monitor CRS. Vasopressor use and doses and respiratory support parameters, which ranged from oxygen support through nasal cannula to continuous positive airway pressure (C-PAP) helmet, were recorded.

FiO2 (Fraction of inspired Oxygen) values were estimated as follows: FiO2 24, 28, 32 and 36\% for nasal cannulae with oxygen flow of 1,2, 3 and $4 \mathrm{~L} / \mathrm{min}$ respectively; FiO2 $40 \%$ for aerosol mask with oxygen flow of $8 \mathrm{~L} / \mathrm{min}$; FiO2 from 24 to $50 \%$ for Venturi mask; FiO2 $100 \%$ for non-rebreathing mask with reservoir bag; FiO2 as set according to manufacturer instructions for helmet C-PAP.

The $\mathrm{SpO} 2$ to FiO2 ratio was calculated as a useful tool for stratification of hypoxia severity in the pediatric population. As previously reported, in the absence of an arterial access, directly measuring 
$\mathrm{PaO} 2$ (Partial Pressure of Oxygen), the $\mathrm{SpO} 2$ to FiO2 ratio shows a good correlation with the FiO2 to $\mathrm{PaO} 2$ ratio $^{15,16}$.

Mann-Whitney statistical test was used for p-value calculation of the efficacy of diclofenac based on the number of febrile peaks during 24 hours with and without diclofenac (the results are shown in table 3 ).

\section{RESULTS}

Five out of the first 10 patients treated with tisagenlecleucel for chemorefractory or post-transplant relapsed B-lineage ALL in our institution, from August 2016 to August 2019, experienced some grade of CRS. Characteristics of the five patients (3 males; median age 5 years, range 3-21 years) are reported in Table 2. Briefly, patients 1, 3, and 4 had relapsed after stem cell transplantation, whereas patient 2 presented with a chemorefractory relapse and patient 5 with a second refractory relapse. Bone marrow blasts upon screening ranged from $15 \%$ to $70 \%$ and at lymphodepletion initiation ranged from $48 \%$ to $70 \%$ in this patient series.

Vital signs monitoring (heart rate, respiratory rate, temperature, blood pressure, $\mathrm{SpO} 2 / \mathrm{FiO} 2$ ) as well as CRP levels, diclofenac, dopamine and noradrenaline doses from the time of CAR-T cell infusion until resolution of CRS have been plotted for each patient in Figure 1 and scored according to three different grading systems Penn, Lee and ASCTC.

Grade 3-4 CRS was observed in four patients, while only one patient presented with grade 1 CRS. Fever, consistently defined as grade $1 \mathrm{CRS}$ among the different grading systems (even if low-grade, i.e. $<37.5^{\circ} \mathrm{C}$ ) was almost invariably associated with shivers, tachycardia, tachypnea and hypotension. Moreover, the maximum interval elapsing between spikes, despite the use of i.v. paracetamol, rarely exceeded three hours.

Patient 1 experienced maximum grade I CRS, according to Penn, Lee and ASCTC, consisting of fever only, requiring antipyretic, including diclofenac. No need for oxygen support, vasopressors nor tocilizumab occurred within the duration of CRS (14 days).

Patient 2 experienced maximum grade $4 \mathrm{CRS}$, according to Penn and grade 3 according to Lee and ASCTC grading. High-dose oxygen (high-flow nasal cannula, HFNC) with FiO2 45\% for almost 5 days (89 hours) and dopamine $10 \mathrm{mcg} / \mathrm{kg} / \mathrm{min}$ for 24 hours were required. 
Patients 3, 4, and 5 presented CRS maximum grade IV, according to Penn, Lee and ASCTC, and required high-dose dopamine (10-12 mcg/kg/min), plus norepinephrine in patient 5, C-PAP in patient 3 and 5 and intubation in patient 4.

Median time to fever onset was 20 hours (range 8-27) after CAR-T infusion, whereas treatment with diclofenac was initiated at a median of 20 hours (median, range 13-33) after fever onset. The starting dose of diclofenac i.v. continous infusion was $0.5 \mathrm{mg} / \mathrm{kg} / \mathrm{day}$, and the dose was escalated/adjusted according to the temperature curves, with a maximum dose of $1 \mathrm{mg} / \mathrm{kg} / \mathrm{day}$.

In order to assess the impact of diclofenac in the management of CRS, firstly, its effectiveness in controlling sustained fever within the first 24 hours after the start of the therapy, compared with the 24 hours prior to diclofenac initiation, was assessed. A decline in fever peaks as compared to baseline was observed in all patients during the first 24 hours after starting treatment with diclofenac (Figure 1). Specifically, the highest median body temperature was significantly lower within 13-24 h after diclofenac infusion started as compared to the early hours of fever onset, where patients remained febrile despite standard anti-pyretic drugs (e.g. paracetamol). Furthermore the efficacy of diclofenac has been assessed as the number of febrile peaks during 24 hours with and without diclofenac: a mean of 3,07 febrile peaks without diclofenac and 0,95 with diclofenac with a p-value of 0,02 (Table 3) have been observed.

Moreover, we hypothesized that fever control by means of diclofenac could provide a beneficial effect on vital parameters and hemodynamic functions. Although some patients still presented with fever, within the first $48 \mathrm{~h}$ hours after starting the infusion of diclofenac a clinical benefit was obtained by hampering progression of tachycardia and tachypnea. Heart rate and respiratory rate were significantly reduced after 48 hours of diclofenac therapy, as compared to the same baseline parameters, just before starting treatment (Figure 1). Conversely, no direct detrimental effect of diclofenac on blood pressure was observed.

Kidney function of all 5 patients was adequate before use of diclofenac and remained normal even after its use. We did not detect any other associated toxicities: no increase of platelet transfusion requirement, no bleeding events.

Whenever diclofenac had to be discontinued (4 events in 3 patients), due to drug infusion incompatibilities in patients with venous access issues, fever invariably occurred, but was promptly controlled upon diclofenac resumption. However, despite fever control, in the following days, four patients presented with severe hemodynamic instability, with hypotension and oliguria, which required 
vasopressors: four patients received dopamine $5-12 \mathrm{mcg} / \mathrm{kg} / \mathrm{day}$, and one patient received also i.v. norepinephrine at $0,1 \mathrm{mcg} / \mathrm{kg} / \mathrm{min}$ for less than 48 hours.

Vasopressors were followed by the administration of tocilizumab ( 1 dose in patient 2 and two doses in patients 3, 4, and 5), the recombinant humanized monoclonal antibody, directed against the interleukin6 receptor, approved by the FDA for treatment of severe or life-threatening CAR-T cell induced CRS. Tocilizumab binds both soluble and membrane-bound IL-6 receptor and inhibits IL-6-mediated signaling through these receptors ${ }^{17}$.

The $\mathrm{SpO} 2 / \mathrm{FiO} 2$ ratio consistently varied along with the severity of $\mathrm{CRS}$, with lower $\mathrm{SpO} 2 / \mathrm{FiO} 2$ values in patients with higher body temperature, heart rate, respiratory rate and CPR values.

A SpO2/FiO2 ratio below 200 was considered among the clinical indicators of severe respiratory distress leading to the decision of ICU admission and invasive mechanical ventilation in patient 4 . Patient 5 was transferred to ICU due to long-lasting refractory fluid overload, jeopardizing his cardio-respiratory dynamics.

Furthermore, a significant increase of CRP was observed in all patients, but rising with different kinetics, according to the evolution of CRS. The highest CRP was reached at a median of 4 days (range 4-8 days), with decreasing values thereafter. However it was not possible to attribute a role to the anti-inflammatory effect of diclofenac, compared with the powerful effect of tocilizumab, in reducing CRP to normal levels. Eventually, CRS resolved at a median of 10 days (range 9-15) and no major sequelae were observed.

\section{DISCUSSION}

NSAIDs are used in pediatrics, even if less frequently than in adults, and have multiple therapeutic indications, the most common ones being fever, pain after surgery, and inflammatory disorders ${ }^{18,19}$. In this study we described the course of CRS in five patients who have been treated with diclofenac for CRS-related fever after tisagenlecleucel infusion for relapse or chemorefractory B-lineage ALL.

The reported incidence of CRS after CAR-T cell therapy overall is highly variable and ranges from 35\% to $93 \%{ }^{20,21,22}$. In the pediatric ALL population CRS was reported in the $77 \%$ of the patients treated with tisagenlecleucel, with $22 \%$ and $27 \%$ presenting grade III and IV, respectively ${ }^{23}$. Time to CRS onset after CAR-T infusion was 3 days (range 1-22) and the median duration 8 days (range 1-36); 39\% of the 
patients required tocilizumab (23\% only one dose and $13 \%$ two doses), with $50 \%$ of the patients being transferred to the ICU and $15 \%$ requiring intubation ${ }^{24}$.

CRS treatment included antipyretics for fever, intravenous fluids and vasopressors for hypotension, besides supportive care for respiratory distress, ranging from low flow oxygen to mechanical ventilation. Vasopressors were reported in the $53 \%$ of the patients enrolled in the expanded access, with $24 \%$ requiring high-doses ${ }^{24}$.

Corticosteroids could mitigate the cytokine storm, but their use was limited due to the risk that the clinical effectiveness of CAR-T cell therapy could be potentially jeopardized by the blocking of $\mathrm{T}$ cell activation, function, and proliferation ${ }^{8,25}$. In the original trial with tisagenleclaucel corticosteroids were administered in $20 \%$ of the treated patients $(16 / 79)^{24}$.

The high-grade CRS occurring in our series of patients was not surprising, due to the high disease burden at the time of lymphodepletion. In the management of fever unresponsive to paracetamol or other NSAIDs, diclofenac i.v. continuous infusion from $0,5 \mathrm{mg} / \mathrm{kg}$ to $1 \mathrm{mg} / \mathrm{kg}$ was planned, according to our standard practice for persistent or refractory fever. Diclofenac was able to control fever, occurring between 12 and 72 hours after tisagenlecleucel infusion and characterized by a very severe profile, sometimes with spikes up to $39-40^{\circ} \mathrm{C}$ every 3-4 hours. In all the 5 patients diclofenac allowed prolonged control of tachycardia and tachypnea, on top of fever control. Despite the initial hemodynamic stability, diclofenac could not prevent CRS progression in 4 out of 5 patients.

We can conclude from our experience that the use of diclofenac had improved patient symptoms and decreased the complexity of patient management, by means of fever control and the consequent improvement of vital parameters, up to the progression of CRS. No toxic effects associated with diclofenac were observed ${ }^{26}$. Moreover diclofenac might have limited / delayed the use of other drugs in the management of CRS by getting rid of fever-associated vital sign impairment.

Mild to severe respiratory failure is among the hallmarks of CRS. Capillary leak is the mechanism underlying hypoxia and lung opacities. CRS-associated fever, however, has a major role in increasing minute ventilation and respiratory distress. We may argue that, in a significant proportion of patients, the increased respiratory workload driven by fever may prompt the decision to proceed with endotracheal intubation and invasive mechanical ventilation. Low-dose diclofenac infusion, through its effect in reducing oxygen consumption, may contribute to reduce non-invasive ventilation failure and prevent ICU admission. We cannot prove or rule out that diclofenac could have had any impact on CRS evolution in our series of patients. The patients in our series, with a high disease burden, became unstable shortly 
after CAR-t cell infusion and, in the absence of diclofenac, their CRS management would have required to anticipate the subsequent steps. Therefore diclofenac serves as first step in CRS management in our institution and may allow subsequent steps to be delayed. We cannot speculate whether the chance to delay tocilizumab could be of some benefit, allowing prolonged IL-6 effects. It is also important to underline that diclofenac did not induce any modifications on CAR-T cells expansion and cytokine pattern during CRS (both factors were routinely monitored after CART infusion).

In conclusion, the use of diclofenac relieved patient's symptoms and decreased the complexity of management by limiting the increased cardio-respiratory workload secondary to fever. Despite CRS progression, fever control and the reduction of its detrimental effect on vital parameters decreased patient discomfort. No conclusions on CRS hampering could be drawn based on this limited series of patients. 


\section{REFERENCES}

1. Gan TJ1. Diclofenac: an update on its mechanism of action and safety profile. Curr Med Res Opin. $2010 \mathrm{Jul} ; 26(7): 1715-31$.

2. Altman R, Bosch B, Brune K, Patrignani P, Young C. Advances in NSAID Development: Evolution of Diclofenac Products Using Pharmaceutical Technology. Drugs. 2015 May;75(8):859-77.

3. Pesenti A, Riboni A, Basilico E, Grossi E. Antipyretic therapy in ICU patients: evaluation of low dose diclofenac sodium. Intensive Care Med. 1986;12(5):370-3.

4. Cormio M, Citerio G, Spear S, Fumagalli R, Pesenti A. Control of fever by continuous, low-dose diclofenac sodium infusion in acute cerebral damage patients. Intensive Care Med. 2000 May;26(5):552-7.

5. Paramba FC1, Naushad VA, Purayil N, Mohammed OH, Chandra P. Randomized controlled study of the antipyretic efficacy of oral paracetamol, intravenous paracetamol, and intramuscular diclofenac in patients presenting with fever to the emergency department. Ther Clin Risk Manag. 2013;9:3716.

6. Gödel P, Shimabukuro-Vornhagen A, Von Bergwelt-Baildon M. Understanding cytokine release syndrome. Intensive Care Med. 2018 Mar;44(3):371-373.

7. Tanaka T, Narazaki M, Kishimoto T. Immunotherapeutic implications of IL-6 blockade for cytokine storm. Immunotherapy 2016; 8:959-970.

8. Teachey DT, Lacey SF, Shaw PA, Melenhorst JJ, Maude SL, Frey N, et al. Identification of predictive biomarkers for cytokine release syndrome after chimeric antigen receptor T-cell therapy for acute lymphoblastic leukemia. Cancer Discov. 2016; 6:664-679.

9. Lee DW, Santomasso BD, Locke FL, Ghobadi A, Turtle CJ, Brudno JN, et al. ASTCT Consensus Grading for Cytokine Release Syndrome and Neurologic Toxicity Associated with Immune Effector Cells. Biol Blood Marrow Transplant. 2019 Apr; 25(4):625-638.

10. Teachey DT, Rheingold SR, Maude SL, Zugmaier G, Barrett DM, Seif AE, et al. Cytokine release syndrome after blinatumomab treatment related to abnormal macrophage activation and ameliorated with cytokine-directed therapy. Blood 2013; 121:5154-5157.

11. Lee DW, Gardner R, Porter DL, Louis CU, Ahmed N, Jensen M, et al. Current concepts in the diagnosis and management of cytokine release syndrome. Blood 2014, 124:188-195. 
12. Kochenderfer JN, Dudley ME, Feldman SA, Wilson WH, Spaner DE, Maric I, et al. B-cell depletion and remissions of malignancy along with cytokine-associated toxicity in a clinical trial of anti-CD19 chimeric-antigen-receptor-transduced T cells. Blood 2012;119:2709-2720

13. Common Terminology Criteria for Adverse Events (CTCAE) - version 5.0 - NCI National Cancer Institute.

14. Porter DL, Hwang WT, Frey NV, Lacey FS, Shaw PA, Loren AW, et al. Chimeric antigen receptor $\mathrm{T}$ cells persist and induce sustained remissions in relapsed refractory chronic lymphocytic leukemia. Sci TranslMed 2015;7:303ra139.

15. Mayordomo-Colunga J, Pons M, López Y, Solana MJ, Rey C, Martinez-Camblor P, et al. Predicting non-invasive ventilation failure in children from the $\mathrm{SpO} 2 / \mathrm{FiO} 2(\mathrm{SF})$ ratio. Intensive Care Med. 2013;39(6):1095-1103.

16. Rice TW, Wheeler AP, Bernard GR, Hayden DL, Schoenfeld DA, Ware LB, et al. Comparison of the $\mathrm{SpO} 2 / \mathrm{FIO} 2$ ratio and the $\mathrm{PaO} 2 / \mathrm{FIO} 2$ ratio in patients with acute lung injury or ARDS. Chest. 2007;132(2):410-417

17. Davila ML, Riviere I,Wang X, Bartido S, Park J, Curran K, et al. Efficacy and toxicity management of 19-28z CAR $\mathrm{T}$ cell therapy in B cell acute lymphoblastic leukemia. Sci Transl Med 2014;6:224ra25.

18. Litalien C, Jacqz-Aigrain E. Risks and benefits of nonsteroidal anti-inflammatory drugs in children: a comparison with paracetamol. Paediatr Drugs. 2001;3(11):817-58.

19. Vuori A, Salo M, Viljanto J, Pajulo O, Pulkki K, Nevalainen T. Effects of post-operative pain treatment using non-steroidal anti-inflammatory analgesics, opioids or epidural blockade on systemic and local immune responses in children. Acta Anaesthesiol Scand. 2004 Jul;48(6):738-49.

20. Brudno JN, Kochenderfer JN. Toxicities of chimeric antigen receptor T cells: Recognition and management. Blood 2016;127:3321-3330.

21. Frey NV, Porter DL. Cytokine release syndrome with novel therapeutics for acute lymphoblastic leukemia. Hematology Am Soc Hematol Educ Program 2016;2016:567-2072Hay KA. Cytokine release syndrome and neurotoxicity after CD19 chimeric antigen receptor-modified (CAR-) T cell therapy. Br J Haematol. 2018 Nov;183(3):364-374. 
22. Hay KA. Cytokine release syndrome and neurotoxicity after CD19 chimeric antigen receptormodified (CAR-) T cell therapy. Br J Haematol. 2018 Nov;183(3):364-374.

23. Maude SL, Laetsch TW, Buechner J, Rives S, Boyer M, Bittencourt H, et al. Tisagenlecleucel in Children and Young Adults with B-Cell Lymphoblastic Leukemia. N Engl J Med. 2018 Feb 1; 378(5): 439-448.

24. Stephan A, Maude SL, Rives S, Baruchel A, Boyer MW, Bittencourt H, et al. Updated Analysis of the Efficacy and Safety of Tisagenlecleucel in Pediatric and Young Adult Patients with Relapsed/Refractory Acute Lymphoblastic Leukemia. Oral talk ASH 2018.

25. Robert Q. Le, Liang Li, Weishi Yuan, Stacy S. Shord, Lei Nie, Bahru A. Habtemariam, Donna Przepiorka, et al. FDA Approval Summary: Tocilizumab for Treatment of Chimeric Antigen Receptor T Cell Induced Severe or Life Threatening Cytokine Release Syndrome. Oncologist. 2018 Aug; 23(8): 943-947.

26. Anderson SK, al Shaikh BA. Diclofenac in combination with opiate infusion after joint replacement surgery. Anaesth Intensive Care. 1991 Nov;19(4):535-8. 


\begin{tabular}{|c|c|c|c|c|c|c|c|c|c|}
\hline & \multicolumn{3}{|c|}{ Hypertension } & \multicolumn{3}{|c|}{ Hypoxia } & \multicolumn{3}{|c|}{ Organ Toxicity } \\
\hline Grade & Penn $^{14}$ & Lee $^{11}$ & ASTCT $^{9}$ & Penn $^{14}$ & Lee $^{11}$ & ASTCT $^{9}$ & Penn $^{14}$ & Lee $^{11}$ & ASTCT $^{9}$ \\
\hline 1 & - & - & - & - & - & - & - & - & NA \\
\hline 2 & - & $\begin{array}{c}1 \mathrm{LD} \\
\mathrm{VP}\end{array}$ & No VP & - & $\begin{array}{c}\mathrm{O} 2 \\
<40 \%\end{array}$ & $\mathrm{O} 2 \leq 6 \mathrm{~L}$ & I-II & II & NA \\
\hline 3 & $\begin{array}{l}1 \mathrm{LD} \\
\mathrm{VP}\end{array}$ & $\begin{array}{c}2 \text { or HD } \\
\text { VP }\end{array}$ & $\begin{array}{c}1 \mathrm{VP} \\
\pm \text { vasopressin }\end{array}$ & $\begin{array}{l}\text { any } \\
\mathrm{O} 2\end{array}$ & $\begin{array}{c}\mathrm{O} 2 \\
\geq 40 \%\end{array}$ & $\begin{array}{c}\mathrm{O} 2>6 \\
\mathrm{~L}\end{array}$ & $\begin{array}{l}\text { III, } \\
\text { trans } \\
\text { IV }\end{array}$ & $\begin{array}{l}\text { III, } \\
\text { LFTs } \\
\text { IV }\end{array}$ & NA \\
\hline 4 & $\begin{array}{c}\geq 2 \text { or } \\
\text { HD } \\
\text { VP }\end{array}$ & $\begin{array}{c}\geq 2 \text { or } \\
\text { HD } \\
\text { VP }\end{array}$ & $\geq 2 \mathrm{VP}$ & intub & intub & $\begin{array}{l}\text { B/C- } \\
\text { PAP/ } \\
\text { intub }\end{array}$ & IV & IV & NA \\
\hline
\end{tabular}

TABLE 1 Synopsis of CRS grading according to the U-Penn, Lee and ASTCT classifications 


\begin{tabular}{|c|c|c|c|c|c|}
\hline & Patient 1 & Patient 2 & Patient 3 & Patient 4 & Patient 5 \\
\hline Age (years) & 21 & 5 & 3 & 7 & 5 \\
\hline Gender & M & $\mathrm{F}$ & M & $\mathrm{F}$ & M \\
\hline Down Syndrome & Yes & Yes & No & No & No \\
\hline Previous SCT (phase at SCT) & Yes (CR2) & No & Yes (CR1) & Yes (CR2) & No \\
\hline Disease phase & $\begin{array}{c}\text { relapse } \\
7 \text { months } \\
\text { post-SCT }\end{array}$ & $\begin{array}{c}1 \text { st } \\
\text { refractory } \\
\text { relapse }\end{array}$ & $\begin{array}{c}\text { relapse } \\
7 \text { months } \\
\text { post-SCT }\end{array}$ & $\begin{array}{c}\text { relapse } \\
16 \text { months } \\
\text { post-SCT }\end{array}$ & $\begin{array}{l}\text { 2nd } \\
\text { refractory } \\
\text { relapse }\end{array}$ \\
\hline $\begin{array}{c}\text { BM blasts upon screening } \\
(\%)\end{array}$ & 15 & 62 & 50 & 70 & 38 \\
\hline $\begin{array}{c}\text { BM blasts at } \\
\text { lymphodepletion }(\%)\end{array}$ & 60 & 70 & 65 & 48 & 58 \\
\hline $\begin{array}{c}\text { CRS day of onset (duration, } \\
\text { days) }\end{array}$ & $+1(14)$ & $+1(10)$ & $+2(10)$ & $+1(15)$ & $+1(14)$ \\
\hline $\begin{array}{l}\text { CRS maximum grade (peak } \\
\text { day) }\end{array}$ & $\mathrm{I}(+1)$ & III $(+4)$ & IV $(+4)$ & IV $(+4)$ & IV $(+7)$ \\
\hline $\begin{array}{c}\text { Numbers of vasosopressors } \\
\text { (duration, days) }\end{array}$ & - & $1(7)$ & $1(7)$ & $1(9)$ & $2(3)$ \\
\hline Tocilizumab doses (day) & - & $1(+4)$ & $\begin{array}{l}2(+4 \text { and } \\
+6)\end{array}$ & $\begin{array}{l}2(+6 \text { and } \\
\quad+7)\end{array}$ & $\begin{array}{c}2(+6 \text { and } \\
+8)\end{array}$ \\
\hline $\begin{array}{l}\text { Methyl-prednisolone } \\
\text { (starting day) }\end{array}$ & No & No & No & Yes $(+8)$ & Yes $(+12)$ \\
\hline Seizures (day) & No & Yes (7) & Yes (7) & Yes (8) & No \\
\hline
\end{tabular}

TABLE 2 Characteristics of the five patients with relapsed/refractory B-ALL experiencing CRS after tisagenlecleucel. 


\begin{tabular}{|c|c|c|l|}
\hline & \multicolumn{2}{|c|}{ Febrile peaks per day (mean) } & \\
\hline Patient $\left(\mathbf{n}^{\circ}\right)$ & Without Diclofenac & With Diclofenac & \\
\hline $\mathbf{1}$ & 3,43 & 0,55 & \\
\hline $\mathbf{2}$ & 2,12 & 0,57 & \\
\hline $\mathbf{3}$ & 2,04 & 1,65 & \\
\hline $\mathbf{4}$ & 5,76 & 0,82 & \\
\hline $\mathbf{5}$ & 2,00 & 1,17 & \\
\hline all pts (mean) & $3,07(1,06-5,07)$ & $0,95(0,38-1,53)$ & $\mathrm{p}$ value: 0,02 \\
\hline
\end{tabular}

TABLE 3 Number of febrile peaks/24 hours measured since the fever started up to the initiation of diclofenac and throughout diclofenac treatment up to tocilizumab, if any: a mean of 3,07 febrile peaks/24 hours without diclofenac and 0,95/24 hours with diclofenac were observed 